\title{
UMA METARREFLEXÃO SOBRE AS PESQUISAS DAS CIÊNCIAS SOCIAIS DA RELIGIÃO A PARTIR DOS DADOS DO CENSO IBGE
}

\author{
Marcelo Camurçal
}

Clara Mafra, dentre os cientistas sociais que estudam o fenômeno religioso no Brasil, arrisco-me a dizer, é a que mais tem chamado a atenção para a necessidade de uma interpretação que contemple as condições de produção do conhecimento sobre o panorama religioso brasileiro a partir do instrumento Censo nacional realizado pelo IBGE. Em artigos, debates, mesas redondas, desde seu pioneiro Censo da Religião: um instrumento descartável ou reciclável? (Mafra, 2004, p. 152-159), ela vem entabulando uma reflexão que se aproxima de uma "sociologia do conhecimento" no sentido que lhe deu Mannheim (1982, p. 51-66), ou seja, uma sociologia dos procedimentos teóricos das ciências sociais que se ocupam da interpretação do campo religioso brasileiro usando os indicadores do Censo nacional operado pelo IBGE.

Muitos dos antropólogos e sociólogos que se ocupam do estudo do fenômeno religioso no Brasil, eu mesmo incluído entre eles, vêm trabalhando de uma forma substantiva e direta os dados dos últimos Censos do IBGE, evidentemente com observações sobre a procedência destes dados, sobre os limites da pesquisa quantitativa e sua relação de complementaridade com a pesquisa qualitativa etc. Mafra, por outro lado, tem se dedicado prioritariamente à tarefa de estranhamento do que significa esta prática de pesquisa com os dados do IBGE, ao exame da relação desigual entre o grande instituto de pesquisa governamental e as iniciativas dos pesquisadores e cientistas sociais (avulsos ou membros de grupos), redes de pesquisa e ONGs - o "rugido do tigre" e o "miado do gato" (Mafra, 2004, p. 159) -, às apropriaçôes, repercussóes e rebatimentos destes números para dentro do campo religioso brasileiro, das instituições e da sociedade brasileira (Mafra, 2013) etc.

1 Antropólogo e docente do Programa de Pós-Graduação em Ciência da Religião e do Programa de Pós-Graduação em Ciências Sociais da Universidade Federal de Juiz de Fora (UFJF). E-mail: mcamurca@terra.com.br

Debates do NER, Porto Alegre, Ano I4, N. 24, P. 85-92, JUl./Dez. 2013 
Nesse texto que agora comento, logo de início sua arguta percepção relativizadora já se faz notar, quando aponta um superdimensionamento em relação aos números do IBGE no que diz respeito à questão da religião no país. Segundo ela, "hipérbole" é o que faz a mídia quando nomeia de "Censo da Religião no Brasil" apenas uma pergunta: "qual a sua religião ou culto?”, contida no rol do questionário do Censo.

O eixo principal de suas consideraçôes nesse texto apresentado a Debates do NER gira em torno de duas proposições. A primeira delas é a de que os pesquisadores do tema da religião no país que trabalham com os dados do Censo referentes a esse quesito, muitas vezes, têm de "buscar fontes subsidiárias e assimétricas para completar a informação indicada pelo número do Censo", que, como se viu acima, é muito restrita. Isso, no seu entender, gera uma "inconsistência metodológica", pois os pesquisadores que trilham esse caminho terminam por "se subordinar a esta condição precária de se apoiar em suas próprias pesquisas, muitas delas qualitativas, para preencher de sentido os números que o Censo oferece". Em vez da estratégia insuficiente de complementar os dados sempre muito gerais e sumários do IBGE por meio dos recursos existentes num nível qualitativo (muitas vezes inadequados, pois se encontram numa outra escala), ela propõe a solicitação ao IBGE, "antes de 2015", de "fontes numéricas mais diversas e precisas sobre as religiōes no Brasil".

Em decorrência disso, como segunda proposição, ela defende a construção de "teorias mais arrojadas", "mais abertas", que, deixando de ser subsidiárias e referenciadas na fixidez dos números oferecidos pelo Censo (modelo "mapa"), incorporassem "alguma incerteza e imprevisibilidade", considerando o "constante movimento" e as "ramificaçôes" que podem ser vislumbrados a partir dos mesmos números se se trabalha com perspectivas "mais ousadas e flexíveis" (modelo "holograma").

Essa postura exigente da autora em relação ao que vêm realizando seus pares assemelha-se, na demanda de não conformismo, à da antropóloga Paula Montero - embora em contexto diverso -, que clamava também por uma "imaginação teórica renovada" (Montero, 1999, p. 338), não cativa das situações empíricas, mas resultado de "acumulação interna de reflexão teórica" (1999, p. 329). 
Gostaria, no entanto, de ressaltar iniciativas e experimentos praticados no âmbito da comunidade de pesquisadores de Ciências Sociais da Religião que não os colocam tão em defasagem com as perspectivas enunciadas e desejadas por Mafra. Mas, antes disso, convém enfatizar a ressalva que ela faz quando diz do seu "pleno conhecimento de que muitas das interpretações que os pesquisadores mencionados fazem dos dados do Censo levam em conta outras pesquisas sérias e consistentes, em metanarrativas teoricamente estabelecidas”. Ela justifica que faz "essas questôes apenas como um estímulo para o pensamento".

Dando prosseguimento a minha ponderação de que os pesquisadores da religião não estão apenas fadados a produzir uma complementação improvisada dos dados sobre religião do IBGE, gostaria de chamar a atenção para uma expertise em termos de pesquisa quantitativa que as Ciências Sociais da Religião no Brasil vêm desenvolvendo desde a década de 1950. Isso as credencia de algum modo - a despeito do que foi sublinhado por Mafra para lidar com as cifras e estatísticas produzidas nos Censos.

Essa trajetória inicia-se com o pioneirismo do sociólogo Cândido Procópio Camargo, com formação na Universidade Católica de Louvain, influenciado pela sociologia religiosa quantitativa de Gabriel Le Bras (Hervieu-Léger; Willaime, 2009, p. 255-286). Suas pesquisas desenvolvidas no Centro Brasileiro de Pesquisas (CEBRAP), fundado por ele, estabelecem um intenso intercâmbio com instrumentos de recenseamento e estatística produzidos por instituições laicas/governamentais e religiosas, tais como: Anuário Estatístico do Brasil, Censos Demográficos do Brasil (1940/1950/1960), Estatísticas do Culto Católico, Estatísticas do Culto Protestante e Boletim Informativo do CERIS (Camargo, 1973; 1961). Seu livro Católicos, Protestantes, Espíritas, uma das primeiras abordagens sociológicas do panorama religioso brasileiro, baseava-se - no que tange à frequência numérica de adeptos das religiōes presentes no Brasil - na tipologia dos grupos religiosos da tabela do IBGE dos Censos de 1940/1950: "Católicos (93,7\%), Protestantes (3,4\%), Espíritas $(1,6 \%)$, Budistas $(0,3 \%)$, Judeus $(0,1 \%)$, Ortodoxos $(0,1 \%)$, Maometanos $(0,0 \%)$, Outros (0,5\%), SR (0,5\%)" (Camargo, 1973, p. 19). 
Seguindo a senda aberta por Camargo nos anos 1960-1970, temos, a partir dos anos 1990, uma sequência de pesquisas quantitativas sobre a situação das religiōes no Brasil, das quais podemos citar: Religiosidade, estrutura social e comportamento político, de Luiz Eduardo Soares e Leandro Piquet Carneiro (1992); A realidade social das religiōes no Brasil, de Antônio Flávio Pierucci e Reginaldo Prandi (1996); Novo Nascimento: os Evangélicos em casa, na igreja e na política, coordenada por Rubem César Fernandes (1998) para o meio evangélico; Desafios do catolicismo na cidade: pesquisa em religióes metropolitanas, coordenada por Luiz Alberto Gómez de Souza e Sílvia Fernandes (2002) para o campo católico; e o rigoroso trabalho estatístico coordenado por César Romero Jacob, que resultou no Atlas de filiação religiosa e indicadores sociais no Brasil (2003). Mais recentemente, uma nova geração de pesquisadores, como Ronaldo Almeida (2004) e Sílvia Fernandes (2011, p. 96-125) vem empregando as pesquisas quantitivas e estatísticas em suas análises.

Sem querer me alongar em referências que podem se tornar muito extensas sobre os diversos campos de pesquisa nas Ciências Sociais da Religião (religião e saúde, religião e política etc.) que utilizam métodos quantitativos e estatísticos, lembro apenas como exemplo ilustrativo desta tendência uma ampla pesquisa coordenada pelo Núcleo de Estudos da Religião (NER) da UFRGS e publicada aqui mesmo, em Debates do NER, no ano de 2001, envolvendo um pool de pesquisadores de universidades diferentes (UFRGS, UNISINOS, PUC/RS, UFMG, UFRJ e UFJF) sobre religião e política entre os estudantes dos cursos de Ciências Sociais (Steil; Alves; Herrera, 2001).

Portanto, os pesquisadores das Ciências Sociais da Religião não precisaram ficar totalmente reféns desses números provenientes do IBGE, que eles não produziram e sobre os quais tiveram pouco controle. Ao contrário, tiveram uma iniciativa autônoma que - apesar das limitações reais apontadas por Mafra - logrou produzir uma interpretação consistente dessas cifras. Por essa razão, foi junto a esses pesquisadores que a mídia brasileira quis repercutir o impacto dos dados censitários vinculados à religião - principalmente nos Censos de 2000 e 2010. Foram diversas entrevistas, artigos, comentários dos antropólogos e sociólogos da religião nos principais órgãos

Debates do NER, Porto Alegre, ANo I4, N. 24, P. 85-92, JUl./DEZ. 2013 
da nossa mídia escrita e televisionada que deram o tom analítico e reflexivo à massa dos dados/estatísticas do Censo. Aplicando também uma "sociologia da sociologia da religião" àquela conjuntura, podemos dizer que foram os pesquisadores das Ciências Sociais da Religião os mais destacados intérpretes dos números do IBGE, produzindo uma "inteligência" dos dados brutos que emergiam dessas estatísticas. Além disso, penso mesmo que alguns desses pesquisadores, como, por exemplo, Antonio Flávio Pierucci, se serviram dessas cifras para produzir novas formulaçōes e argumentos para suas análises do panorama religioso no Brasil, como "sociologia do catolicismo declinante" (Pierucci, 2004, p. 17-28); "religião como ruptura", "religião com solvente" (Pierucci, 2006, p. 17-34). Indo um pouco mais além, penso ainda que os dados do Censo IBGE foram convocados por esses pesquisadores para subsidiar, ilustrar e agregar material empírico ao debate que transcorria dentro do campo acadêmico das Ciências Sociais da Religião, debate este que preexistia à visibilidade que tomaram esses dados: "secularização x reencantamento"; "trânsito religioso"; "dupla/múltipla pertença religiosa"; "mercado de bens simbólicos"; "papel da religião no espaço público"; etc.

Mafra, nesse artigo que comento, é um exemplo do que estou chamando desta autonomia epistemológica do pesquisador da religião face aos números do IBGE, pois, munida de suas pesquisas qualitativas, do conhecimento acumulado a partir delas e do emprego de ferramentas teóricas das disciplinas antropológica e sociológica, empreende uma criativa hermenêutica dos dados frios provenientes do último Censo de 2010.

De um lado, no caso do decréscimo numérico da Igreja Universal de Reino de Deus (IURD) indicado nas cifras do último Censo (perda provável de 228 mil fiéis de 2000 a 2010), ela vai produzir uma interessante análise do que está por trás daquilo que esses números escondem. Ao associar a queda numérica dos adeptos declarantes da IURD ao crescimento desmesurado dos "evangélicos não determinados", aliado à informação de que a IURD sempre teve entre seus frequentadores um público pentecostal flutuante, Mafra termina por concluir que "o inchaço da categoria 'evangélico não determinado' no último Censo bem pode ser indicativo de uma rotinização da influência mais abrangente da Universal em todo o campo 
evangélico, e não indicação da redução de sua influência”. De outro lado, no caso do expressivo número dos "sem religiáo", que continua a crescer neste último Censo, Mafra vai desenvolver sua argumentação a partir do que esses números revelam. Ao contrário do que estava consolidado em muitas pesquisas no campo das Ciências Sociais da Religião, enquanto interpretação sobre esses "sem religião" como expressão de um perfil de jovens, classe média, secularizados, o que os números do último Censo mostram é que “a maioria dos 'sem religião' tem baixa escolaridade, está na base da pirâmide e é de cor parda” (p.7). O que Mafra sugere como interpretação é que esse grupo, na base da pirâmide social, de baixa escolaridade e de cor parda, sintomaticamente características dos pentecostais, pode ser egresso dessas camadas pentecostais - aqueles que não frequentam mais seus cultos e sua rígida ética (são "desviados"), mas ainda partilham de alguma forma de suas crenças anteriores, como aquela em Deus.

Encontra-se aqui, realizado pela própria Clara Mafra, um exemplo de perspectiva teórica "mais arrojada", que ela cobra desenvolver-se no campo acadêmico das Ciências Sociais da Religião. Por outro lado, é fato que existem abordagens mais esquemáticas e repetidoras de modo literal dos números dos Censos; mas o que penso que vai prevalecer no nosso campo acadêmico deverá ser definido na dinâmica do debate estabelecido no seu interior.

Porém, esta minha relativização sobre aspectos da postulação de Clara Mafra não retira a importância do alerta que ela deflagra. Se nós, os pesquisadores das Ciências Sociais da Religião, ainda não conseguimos obter do IBGE uma ampliação, extensão e melhor qualificação dos dados sobre religião nos Censos para que nossa interpretação possa ter um alcance maior, dispensando a especulação e o recurso a uma comparação possível por meio dos dados obtidos nas nossas próprias pesquisas em escala muito menor, Mafra tem toda a razão no seu diagnóstico e proposta! Dessa forma, sou inteiramente a favor da exigência ao IBGE do fornecimento de dados mais amplos e precisos. Aliás, orgulho-me de estar citado num dos textos de Mafra como um dos que - já historicamente - demandaram isto ao IBGE em relação ao Censo de 1990 (Mafra, 2004, p. 155). 
Por fim, os ajustes que procurei desenvolver neste meu comentário às problematizaçôes lançadas por Clara Mafra de maneira nenhuma desconsideram o teor instigador de seu repto. $\mathrm{Na}$ verdade, eles funcionam mais como "notas de pé de página" e contextualizaçôes para temperar o cerne do seu argumento, sem contraditá-lo, mas apresentando adendos que entendo que possam ser levados em conta.

\section{REFERÊNCIAS}

ALMEIDA, Ronaldo de. Religião na metrópole paulista. Revista Brasileira de Ciências Sociais, v. 19, n. 56, 2004.

CAMARGO, Cândido Procópio. Católicos, Protestantes e Espiritas. Petrópolis: Vozes, 1973.

Kardecismo e Umbanda. São Paulo: Pioneira, 1961.

FERNANDES, Rubem César et al. Novo Nascimento: os evangélicos em casa, na igreja e na política. Rio de Janeiro: Mauad, 1998.

FERNANDES, Sílvia. Marcos definidores da condição juvenil para católicos e pentecostais na Baixada Fluminense: algumas proposições a partir de um survey. Religião e Sociedade, v. 31, n. 1, 2011, p. 96-125, 2011.

GOMEZ DE SOUZA, Luiz Alberto; FERNANDES, Sílvia. Desafios do catolicismo na cidade: pesquisa em regiōes metropolitanas brasileiras. São Paulo: Paulus, 2002.

HERVIEU-LÉGER, Danièle; WILLAIME, Jean-Paul. Gabriel Le Bras 1891-1970. In: Sociologia e Religião: abordagens clássicas. Aparecida, São Paulo: Ideias \& Letras, 2009. p.255-286.

JACOB, Cesar Romero et al. Atlas da filiação religiosa e indicadores sociais no Brasil. Rio de Janeiro: EDPUC; São Paulo: Loyola, 2003.

MAFRA, Clara. Censo da Religião: um instrumento descartável ou reciclável? Religião e Sociedade, v. 24, n. 2, p. 152-159, 2004. 
O que os homens e as mulheres podem fazer com números que fazem coisas. In: TEIXEIRA, Faustino; MENEZES, Renata (Orgs.). Religiōes em movimento: as religiōes no censo de 2010. Petrópolis: Vozes, 2013. No prelo.

MANNHEIM, Karl. A posição da sociologia. In: Mannheim - Sociologia. São Paulo: Ática, 1982. p. 51-67.

MONTERO, Paula. Religiōes e dilemas da sociedade brasileira. In: $O$ que ler na ciência social brasileira (1970-1995). v. 1 Antropologia. Brasília: Ed. Sumaré/ANPOCS/CAPES, 1999. p. 327-367.

PIERUCCI, Antonio Flávio. Bye bye, Brasil: o declínio das religões tradicionais no Censo 2000. Estudos Avançados, v. 18, n. 52, p.17-28, 2004.

. Ciências Sociais e Religião: a religião como ruptura. In: TEIXEIRA, Faustino; MENEZES, Renata (Orgs.). As religiōes no Brasil: continuidades e rupturas. Petrópolis: Vozes, 2006. p.17-34.

PIERUCCI, Antonio Flávio; PRANDI, Reginaldo. A realidade social das Religiões no Brasil. São Paulo: Hucitec, 1996.

PIQUET CARNEIRO, Leandro; SOARES, Luís Eduardo. Religiosidade, estrutura social e comportamento político. In: BINGEMER, Maria Clara (Org.). O impacto da modernidade sobre a religião. São Paulo: Loyola, 1992.

STEIL, Carlos; ALVES, Daniel; HERRERA, Sonia. Religião e Política entre os alunos de Ciências Sociais. Debates do NER, n. 2, p. 09-35, 2001. 